\title{
Highly Efficient Adsorption of Aqueous Pb(II) with Mesoporous Metal-Organic Framework-5: An Equilibrium and Kinetic Study
}

\author{
José María Rivera, ${ }^{1}$ Susana Rincón, ${ }^{2}$ Cherif Ben Youssef, ${ }^{3}$ and Alejandro Zepeda ${ }^{4}$ \\ ${ }^{1}$ Facultad de Ciencias Químicas, Universidad Veracruzana, Prolongación Oriente 6, No. 1009 Colonia Rafael Alvarado, \\ 94340 Orizaba, VER, Mexico \\ ${ }^{2}$ Instituto Tecnológico de Mérida, Av. Tecnológico km 4.5, 97118 Mérida, YUC, Mexico \\ ${ }^{3}$ Instituto Tecnológico de Cancún, DEPI, Av. Kabah km 3, 77500 Cancún, QROO, Mexico \\ ${ }^{4}$ Facultad de Ingeniería Química, Universidad Autónoma de Yucatán, Campus de Ingenierías y Ciencias Exactas, \\ Periférico Norte km 33.5, 97203 Mérida, YUC, Mexico \\ Correspondence should be addressed to Alejandro Zepeda; zepeda74@yahoo.com
}

Received 18 August 2016; Accepted 4 October 2016

Academic Editor: Shu Seki

Copyright @ 2016 José María Rivera et al. This is an open access article distributed under the Creative Commons Attribution License, which permits unrestricted use, distribution, and reproduction in any medium, provided the original work is properly cited.

\begin{abstract}
Mesoporous metal-organic framework-5 (MOF-5), with the composition $\mathrm{Zn}_{4} \mathrm{O}(\mathrm{BDC})_{3}$, showed a high capacity for the adsorptive removal of $\mathrm{Pb}(\mathrm{II})$ from $100 \%$ aqueous media. After the adsorption process, changes in both morphology and composition were detected using a scanning electron microscope (SEM) equipped with an energy dispersive X-ray (EDX) system, Fourier transform infrared spectroscopy (FTIR), and X-ray photoelectron spectroscopy (XPS) analysis. The experimental evidence showed that Zn(II) liberation from MOF-5 structure was provoked by the water effect demonstrating that $\mathrm{Pb}$ (II) removal is not due to ionic exchange with $\mathrm{Zn}$. A kinetic study showed that $\mathrm{Pb}$ (II) removal was carried out in $30 \mathrm{~min}$ with a behavior of pseudo-second-order kinetic model. The experimental data on $\mathrm{Pb}(\mathrm{II})$ adsorption were adequately fit by both the Langmuir and BET isotherm models with maximum adsorption capacities of 658.5 and $412.7 \mathrm{mg} / \mathrm{g}$, respectively, at $\mathrm{pH} 5$ and $45^{\circ} \mathrm{C}$. The results of this work demonstrate that the use of MOF-5 has great potential for applications in environmental protection, especially regarding the removal of the lead present in industrial wastewaters and tap waters.
\end{abstract}

\section{Introduction}

As a result of intensive industrial activity, wastewaters have been increasingly contaminated by heavy metals capable of causing severe health and environmental problems. These undesired wastes are principally formed in the industrial production of fertilizers, batteries, paints, ceramics, glass, explosives, and photography products, as well as metal-extractive industries $[1,2]$. Once heavy metals are introduced into living organisms (including humans), they tend to accumulate and promote a variety of physiological disorders [1]. Lead, in particular, is one of the most disturbing metals in the environment and is considered highly dangerous in terms of environmental risk. Exposure to lead can cause mental deficiency, convulsions, and reduction in hemoglobin production, which may cause anemia $[3,4]$. To prevent environmental exposure, the US Environmental Protection Agency [5] has established a maximum concentration of $\mathrm{Pb}(\mathrm{II})$ in drinking water of $0.015 \mathrm{mg} / \mathrm{L}$. As a consequence, industrial effluents containing high lead concentrations must be treated before being discharged into water bodies.

Different techniques are used to eliminate $\mathrm{Pb}$ (II) from wastewaters, including chemical precipitation, membrane filtration, ion-exchange resins, solvent extraction, adsorption, and coprecipitation [6-8]. However, the applications of these methods in some cases are costly with disadvantages such as incomplete removal and the generation of toxic wastes that require further treatment [7]. Adsorption, in particular, has shown promising results in water treatment in terms of easy operation, high removal efficiency, and its applicability for various pollutants. So far, different materials for removal 
of $\mathrm{Pb}(\mathrm{II})$ of water and wastewater by adsorption have been reported, such as dry desulfurization slag [9], magnetic modified sugarcane bagasse [10], hydroxyapatite [11], biochar-alginate capsule [12], and chitosan/Fe-hydroxyapatite nanocomposite [13]. The porous materials are generally considered as efficient adsorbents for organic compounds and heavy metals [14-16].

Recently, a new class of mesoporous materials called metal-organic frameworks (MOFs) have attracted considerable attention as they combine properties of both organic and inorganic materials $[15,16]$. Various studies using MOFs as adsorbent material for gas and organic compound removal have shown good adsorption capacities [17-24]. However, only few studies have used MOFs as adsorbent material for heavy metal adsorption in aqueous media, and there is therefore scarce information about the possible interaction mechanisms between the adsorbent and the adsorbate. In particular, Bakhtiari and Azizian [25] have recently presented evidence of $\mathrm{Cu}^{2+}$ adsorption in aqueous media with MOF-5 (consists of $\mathrm{Zn}_{4} \mathrm{O}$ inorganic moiety that acts as secondary building unit, coordinating to benzene 1,4-dicarboxylate, a bidentate ligand that acts as spacers, to form a three-dimensional structure). The authors suggested that the obtained $290 \mathrm{mg} / \mathrm{g}$ of $\mathrm{Cu}^{2+}$ maximum adsorption capacity may be explained by the heterogenic surface of MOF- 5 which contains different active sites for adsorption. However, they did not reveal sufficient information to explain the possible mechanisms of adsorption or interactions between adsorbent and adsorbate, as well as the effect of water (at 100\%) on the morphology and structure of MOF- 5 when it is known that, from $4 \%$ of water, MOF-5 may present changes in the crystalline morphology, superficial area, and pore size $[21,26]$.

In this context, we found it necessary to further investigate the constitutive bonding interactions as well as the structural stability in aqueous media of the MOFs, in particular MOF-5. The main objective of this study was to better understand the behavior of MOF-5 during the adsorption process in aqueous media. For this purpose, MOF-5 was synthesized, characterized, and used as adsorbent material for the removal of $\mathrm{Pb}$ (II) from aqueous media (100\%). The adsorption kinetics, $\mathrm{pH}$ influence, isotherms, and surface chemistry were investigated.

\section{Material and Methods}

2.1. Reagents. All reactants and solvents were purchased from the Aldrich Chemical Co. MOF-5 was synthesized in a glass reactor equipped with reflux condenser and Teflon-lined stirrer; $2 \mathrm{~g}$ of terephthalic acid and $9.31 \mathrm{~g}$ of zinc nitrate hexahydrate were dissolved in $60 \mathrm{~mL}$ of $N, N^{\prime}$-dimethylformamide (DMF) solution and heated up to $150^{\circ} \mathrm{C}$ for $4 \mathrm{~h}$. After that, the product was cooled down to room temperature. The $\mathrm{Pb}$ (II) solutions were obtained by dilution from a stock solution containing $1000 \mathrm{mg} \mathrm{Pb}(\mathrm{II}) / \mathrm{L}$ to obtain metal concentrations from 30 to $200 \mathrm{mg} / \mathrm{L}$. Aqueous solutions containing $0.1 \mathrm{M}$ $\mathrm{HCl}$ and $0.1 \mathrm{M} \mathrm{NaOH}$ were used to determine the removal capacity of $\mathrm{Pb}(\mathrm{II})$ at different $\mathrm{pH}$ values.
2.2. Characterizations. The size, morphology, and chemical composition of MOF-5 before and after the adsorption process were analyzed using a scanning electron microscope (SEM). The SEM was equipped with an energy dispersive Xray (EDX) system (Phillips XL30 model). Fourier transform infrared spectroscopy (FTIR) was achieved by the Thermo Nicolet Nexus 670 FT-IR spectrometer using KBr pellets. X-ray photoelectron spectroscopy (XPS) was achieved by the Thermo Scientific K-alpha spectrometer. Powder X-Ray Diffraction (XRD) patterns were obtained in a Bruker D8Advance instruments with $40 \mathrm{kV}, 30 \mathrm{~mA}$ for $\mathrm{Cu}_{\mathrm{K} \alpha}(\lambda=$ $1.5416 \AA$ ) radiation, with a scan speed of $1^{\circ} / \mathrm{min}$ and a step size of $0.02^{\circ}$ in $2 \theta$.

2.3. Adsorptive Removal of $\mathrm{Pb}(\mathrm{II})$ from Aqueous Media. MOF-5 $(0.025 \mathrm{~g})$ was weighed into an Erlenmeyer flask. Solutions $(100 \mathrm{~mL})$ of $\mathrm{Pb}(\mathrm{II})$ with concentrations ranging from 30 to $100 \mathrm{mg} / \mathrm{L}$ were used at initial $\mathrm{pH}$ at 5 , without addition of $\mathrm{NaOH}$ or $\mathrm{HCl}$, with a stirring velocity at $200 \mathrm{rpm}$ for $6 \mathrm{~h}$. All of the studies were carried out at 27,35 , and $45^{\circ} \mathrm{C}$. After $6 \mathrm{~h}$, centrifugation (15000 rpm during $20 \mathrm{~min}$ ) was used to separate the MOF- 5 from the solution, and filtration was performed using a nylon membrane with a $0.22 \mu \mathrm{m}$ pore size. The obtained solution was used for the measurement of $\mathrm{Pb}(\mathrm{II})$ concentration. To monitor the adsorption kinetics, samples were taken at various time intervals from an Erlenmeyer flask with an initial concentration of $200 \mathrm{mg} \mathrm{Pb}(\mathrm{II}) / \mathrm{L}$, reacted at a $\mathrm{pH}$ of 5 and a stirring rate of $200 \mathrm{rpm}$ for $6 \mathrm{~h}$. To evaluate the possible liberation of $\mathrm{Zn}$ (II) due to aqueous conditions $(100 \%)$, an additional set of experiments was performed under the same previous experimental conditions but without addition of $\mathrm{Pb}$ (II). The $\mathrm{Pb}(\mathrm{II})$ and $\mathrm{Zn}$ (II) concentrations were measured by flame atomic absorption using a Perkin Elmer AA800 spectrometer. All experiments were conducted at least in triplicate.

The adsorption capacity at equilibrium $q_{e}$ (in $\mathrm{mg} / \mathrm{g}$ ) was calculated using the following relation:

$$
q_{e}=\frac{\left(C_{0}-C_{e}\right) \times V}{W},
$$

where $C_{0}$ is the initial concentration of $\mathrm{Pb}(\mathrm{II})(\mathrm{mg} / \mathrm{L}), C_{e}$ is the equilibrium concentration of $\mathrm{Pb}(\mathrm{II})(\mathrm{mg} / \mathrm{L}), V$ is the volume of the aqueous solution (L), and $W$ is the weight of MOF-5 (g).

\section{Results and Discussion}

\subsection{Characterization of MOF-5 before and after the $\mathrm{Pb}(\mathrm{II})$ Adsorption Process}

3.1.1. SEM and EDX Characterization. The morphology of MOF-5 and its chemical composition were determined before and after the $\mathrm{Pb}$ (II) adsorption process using a SEM (Figure 1) equipped with an EDX (Figure 3) and XRD (Figures 1S and 2). The images obtained by SEM before $\mathrm{Pb}(\mathrm{II})$ removal (Figure 1(a)) show not well defined structure of MOF-5. Additionally Figure 2(a) shows the disappearance of the peak at $6.9^{\circ}$ and the decrease of intensity of peak at $9.7^{\circ}$. This 


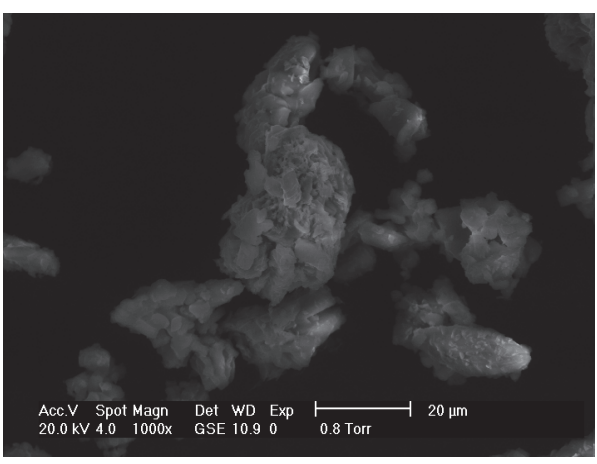

(a)

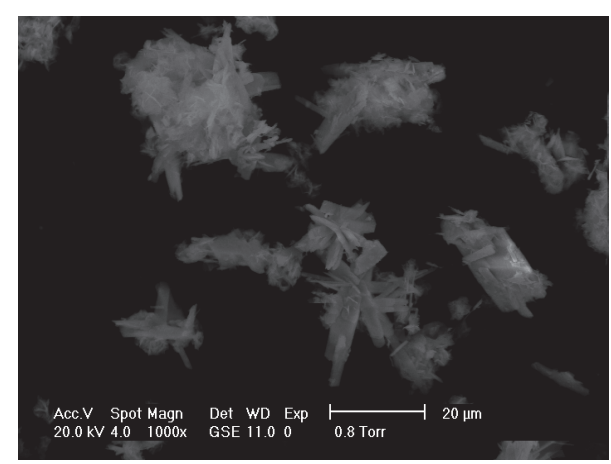

(b)

FIgURE 1: SEM images of MOF-5; (a) before Pb(II) adsorption; (b) after Pb(II) adsorption.

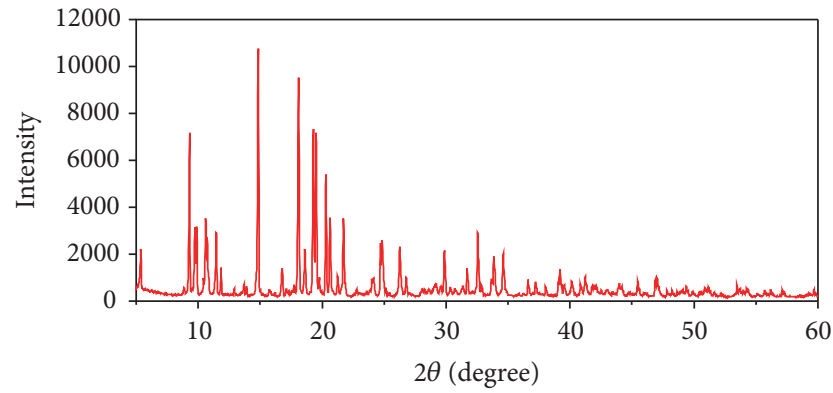

(a)

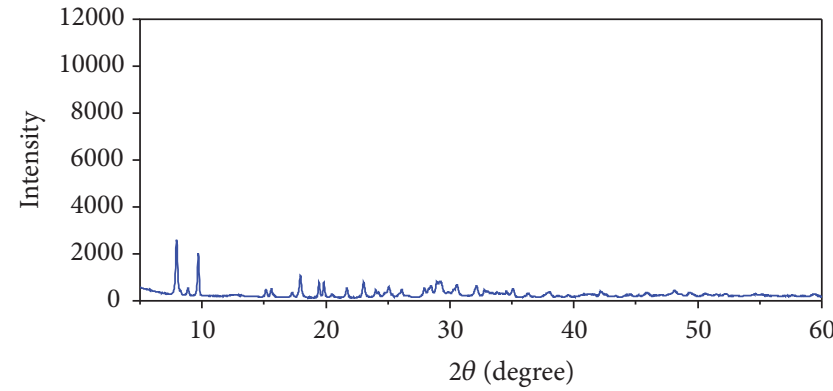

(b)

FIGURE 2: XRD pattern of MOF-5; (a) before $\mathrm{Pb}(\mathrm{II})$ adsorption; (b) after $\mathrm{Pb}$ (II) adsorption.

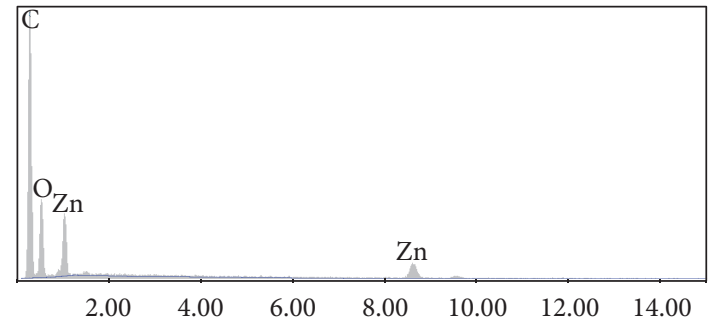

(a)

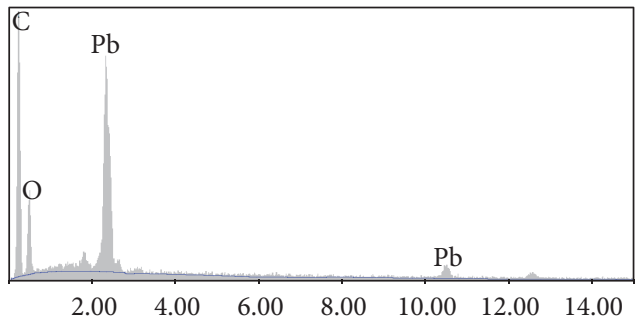

(b)

Figure 3: EDX spectra of MOF-5; (a) before $\mathrm{Pb}(\mathrm{II})$ adsorption; (b) after $\mathrm{Pb}$ (II) adsorption.

occurrence may be due to humidity adsorption (presence of water) as reported by Rodríguez et al. [26]. However the XRD pattern obtained after the synthesis of MOF-5 (Figure $1 \mathrm{~S}$ ) shows the MOF-5 characteristic peaks at $6.9^{\circ}$ and $9.7^{\circ}$ corresponding to a trigonal symmetry as reported in [30]. After $\mathrm{Pb}$ (II) removal, a significant change in the MOF-5 morphology took place resulting in a complex twinning rodshaped material (Figure 1(b)). Moreover, significant changes occurred in the XRD pattern, where the disappearance of peak at $6.9^{\circ}$ and a low intensity of peak at $9.7^{\circ}$ (Figure 2(b)) were observed. These changes may be explained by the effect of the aqueous medium on MOF-5. Greathouse and Allendorf [31] observed that at low water content the MOF5 structure is maintained and that at higher water contents,
$3.9 \%$ and $9.5 \%$, the MOF- 5 structure collapsed. This instability may lead to changes in pore size, material structure, surface area, and material diffusion [26, 32-36].

The results of EDX analysis before and after $\mathrm{Pb}(\mathrm{II})$ removal (Figures 3(a) and 3(b)) showed that after the adsorption process, the entirety of the $9.78 \%$ mass component of $\mathrm{Zn}(\mathrm{II})$ is missing, while $\mathrm{Pb}(\mathrm{II})$ amounting to $32.86 \%$ by mass has been adsorbed by the MOF-5 (Table 1). In order to better explain the liberation of $\mathrm{Zn}$ (II) shown by the EDX analysis, complementary experiments were realized according to the methodology previously described $(100 \mathrm{~mL}$ volume, $\mathrm{pH} 5.6$, and $0.025 \mathrm{~g} \mathrm{MOF}-5)$ in the absence and presence of $\mathrm{Pb}(\mathrm{II})$. It was observed that the liberated $\mathrm{Zn}(\mathrm{II})$ was $63.7 \pm 1.7 \mathrm{mg}$ $\mathrm{Zn}(\mathrm{II}) / \mathrm{L}$ in both cases. These results indicate that $\mathrm{Pb}(\mathrm{II})$ 
TABLE 1: EDX composition of MOF-5 before and after the removal of $\mathrm{Pb}$ (II).

\begin{tabular}{lccccc}
\hline & MOF-5 before removal of $\mathrm{Pb}(\mathrm{II})$ & & \multicolumn{2}{c}{ MOF-5 after removal of Pb(II) } \\
Element & Mass (\%) & Atom (\%) & Element & Mass (\%) & Atom (\%) \\
\hline $\mathrm{C}$ & 68.21 & 78.77 & $\mathrm{C}$ & 53.18 & 13.96 \\
$\mathrm{O}$ & 22.01 & 19.08 & $\mathrm{O}$ & 0 & 15.98 \\
$\mathrm{Zn}$ & 9.78 & 2.15 & $\mathrm{Zn}$ & 32.86 & 0 \\
$\mathrm{~Pb}$ & 0 & 0 & $\mathrm{~Pb}$ & 2.91 \\
\hline
\end{tabular}

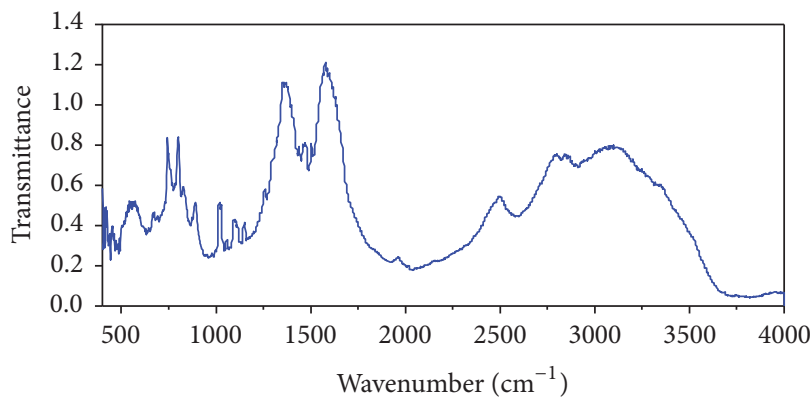

(a)

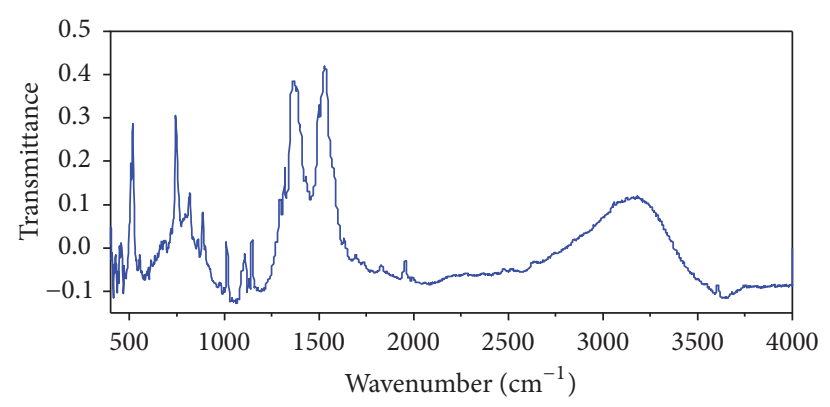

(b)

FIGURE 4: FTIR spectra of MOF-5; (a) before $\mathrm{Pb}$ (II) adsorption; (b) after $\mathrm{Pb}$ (II) adsorption.

incorporation and the liberation of $\mathrm{Zn}(\mathrm{II})$ result from an adsorption process on the MOF- 5 surfaces and that no ionic exchange took place, as has been the case in other reported studies [37]. The loss of $\mathrm{Zn}$ (II) in the MOF-5 structure may be due to the coordination of the $\mathrm{Zn}$ (II) contained in the $\mathrm{Zn}_{4} \mathrm{O}$ complexes with the oxygen atoms of the water through unbonded (electrostatic and van der Waals) interactions [31], provoking the liberation of benzene dicarboxylate ion $\left(\mathrm{BDC}^{2-}\right)$ which directly interacts with $\mathrm{Pb}(\mathrm{II})$.

3.1.2. FTIR Characterization. The infrared spectra of MOF5 samples before and after the $\mathrm{Pb}(\mathrm{II})$ adsorption process are presented in Figure 4. For the sample of adsorbent material before the adsorption process, the characteristic MOF-5 signals observed at 1587 and $1359 \mathrm{~cm}^{-1}$ (Figure 4(a)) correspond to the asymmetric and symmetric stretching of the C-O bond of the carboxylate group directly bonded to $\mathrm{Zn}$, respectively $[38,39]$. It is observed that for the sample extracted at the end of the adsorption process (Figure 4(b)), the signal at $1587 \mathrm{~cm}^{-1}$ shifted to $1530 \mathrm{~cm}^{-1}$. This change may be explained by the absence of $\mathrm{Zn}$ and by the union of the $\mathrm{C}-\mathrm{O}$ bond of the carboxylate group to $\mathrm{Pb}$, which is in accordance with the results of the EDX analysis. It has to be noticed that little absorption is observed for the coordination compounds in the 1800 to $2200 \mathrm{~cm}^{-1}$ range where only vibrations of $\mathrm{C}-\mathrm{O}$ elongation are visible [40]. A characteristic signal of a CO metallic group is observed at $1955 \mathrm{~cm}^{-1}$ for both samples. Furthermore, the small bands observed in the 950 to $1225 \mathrm{~cm}^{-1}$ range (Figures $4(\mathrm{a})-4(\mathrm{~b})$ ) correspond to the flexion of the plane of the $\mathrm{C}-\mathrm{H}$ group present in the benzene ring of the BDC linker. The bands observed at 806 and $763 \mathrm{~cm}^{-1}$ are due to the flexion outside the plane of the
$\mathrm{C}-\mathrm{H}$ group present in the benzene ring of the BDC linker, and only differences in the intensity of the signals before and after $\mathrm{Pb}$ (II) adsorption are observed [41]. The wide bands observed at 3090 and $3161 \mathrm{~cm}^{-1}$ (Figures 4(a)-4(b)) correspond to the $\mathrm{O}-\mathrm{H}$ group of the water and indicate the presence of humidity that is frequently located in the metal coordination [42].

3.1.3. XPS Characterization. The XPS pattern of MOF-5 samples before (Figure 5(a)) and after (Figure 5(b)) the $\mathrm{Pb}$ (II) adsorption process shows peaks at 284.4 and $284.27 \mathrm{eV}$ for C $1 \mathrm{~s}$ and at 532.04 and $531.09 \mathrm{eV}$ for O 1s, respectively. The XPS pattern of $\mathrm{Zn} 2 \mathrm{p}$ in MOF-5 is deconvolved into two peaks with binding energies assigned to $\mathrm{Zn} 2 \mathrm{p}_{3 / 2}$ at $1022-1021.98 \mathrm{eV}$ and to $\mathrm{Zn} 2 \mathrm{p}_{1 / 2}$ at $1045.58-1045.19 \mathrm{eV}$. This is an indication of the presence of the BDC linker coordination which corresponds to the framework groups of the zinc carboxylate $[43,44]$. Additionally, a significant decrease of the peaks intensity was observed after $\mathrm{Pb}$ (II) adsorption (Figure 5(b)), confirming the liberation of $\mathrm{Zn}$ (II). Furthermore, the signal located at $138.25 \mathrm{eV}$ and corresponding to $\mathrm{Pb} 4 \mathrm{f}$ indicates the presence of lead in the adsorbent material, as reported in the formation of $\mathrm{PbO}[45,46]$.

Based on the evidence obtained by Greathouse and Allendorf [31], we propose in this study a possible mechanism for $\mathrm{Pb}$ (II) adsorption on MOF- 5 in aqueous media. The water molecules that are penetrating the MOF- 5 pores provoke interactions between $\mathrm{Zn}$ ions and the oxygen atoms of the water through unbonded (electrostatic and Van der Waals) interactions due to the fact that substituents in tetrahedral complexes $\left(\mathrm{Zn}_{4} \mathrm{O}\right)$ are usually very labile. This phenomenon provokes in turn the formation of $\mathrm{BDC}^{2-}$, which in direct interaction with $\mathrm{Pb}(\mathrm{II})$ participates in the formation of 


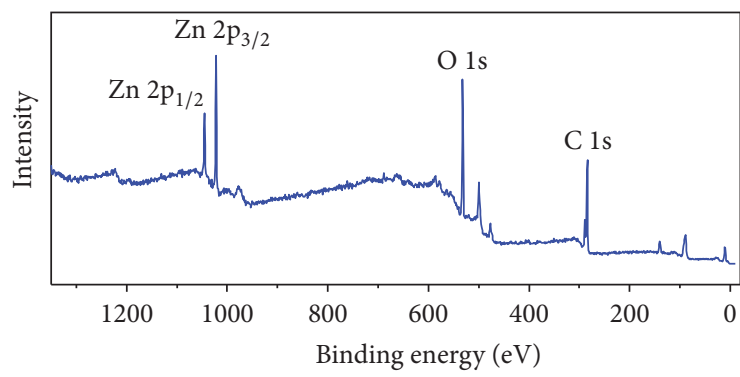

(a)

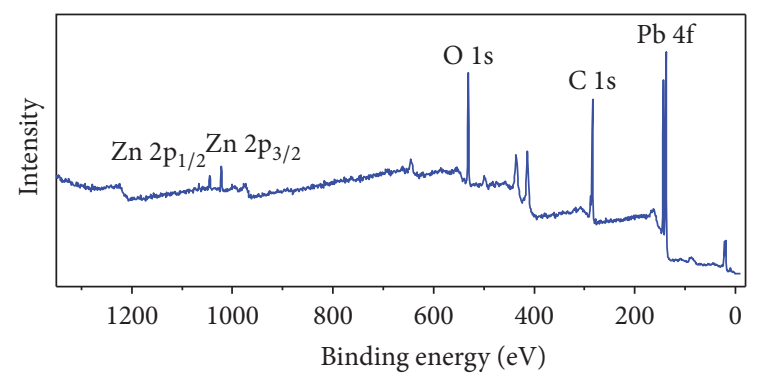

(b)

FIgURE 5: XPS spectra of MOF-5; (a) before Pb(II) adsorption; (b) after Pb(II) adsorption.

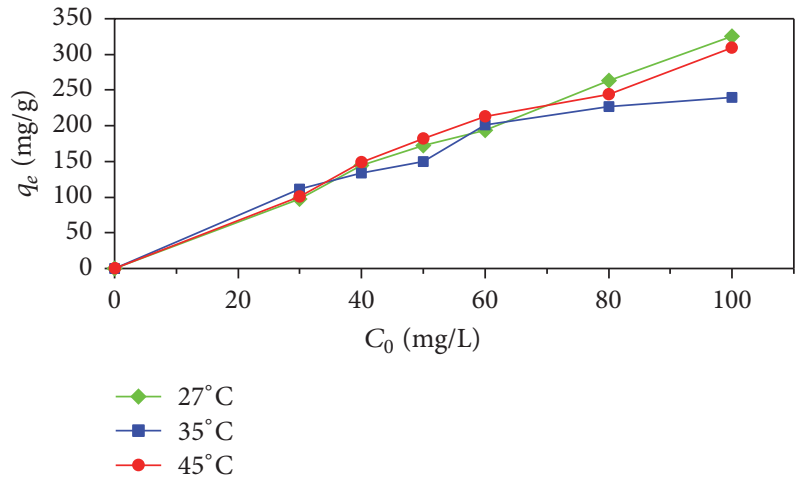

FIGURE 6: Temperature effect on the $\mathrm{Pb}(\mathrm{II})$ adsorption capacity $\left(q_{e}\right)$ onto MOF-5 at different initial $\mathrm{Pb}(\mathrm{II})$ concentrations $\left(C_{0}\right)$ at $\mathrm{pH} 5$ and $6 \mathrm{~h}$ of contact time.

PbBDC structures according to the possible mechanism (ignoring associated hydrolysis reactions):

$$
\begin{aligned}
& \left(\mathrm{Zn}_{4} \mathrm{O}\right)(\mathrm{BDC})_{3}+4 \mathrm{H}_{2} \mathrm{O} \\
& \longrightarrow\left[\left(\mathrm{Zn}_{4} \mathrm{O}\right)\left(\mathrm{H}_{2} \mathrm{O}\right)_{4}(\mathrm{BDC})_{2}\right]^{2+}+\mathrm{BDC}^{2-} \\
& {\left[\left(\mathrm{Zn}_{4} \mathrm{O}\right)\left(\mathrm{H}_{2} \mathrm{O}\right)_{4}(\mathrm{BDC})_{2}\right]^{2+}+\mathrm{BDC}^{2-}+\mathrm{Pb}^{2+}} \\
& \longrightarrow\left[\left(\mathrm{Zn}_{4} \mathrm{O}\right)\left(\mathrm{H}_{2} \mathrm{O}\right)_{4}(\mathrm{BDC})_{2}\right]^{2+}+\mathrm{PbBDC}
\end{aligned}
$$

3.2. Effect of Temperature $\left(27,35\right.$, and $\left.45^{\circ} \mathrm{C}\right)$ on $\mathrm{Pb}$ (II) Removal. To study the removal mechanism, superficial properties, and the affinity of MOF-5 for $\mathrm{Pb}(\mathrm{II})$, studies were carried out at 27,35 , and $45^{\circ} \mathrm{C}$ for $6 \mathrm{~h}$ at $\mathrm{pH} 5$ using a range of initial $\mathrm{Pb}(\mathrm{II})$ concentrations $(30,40,50,60,80$, and $100 \mathrm{mg} / \mathrm{L})$. The evolution of the adsorption capacity $\left(q_{e}\right)$ versus the initial concentration of $\mathrm{Pb}(\mathrm{II})$ (Figure 6) exhibited a directly proportional relationship, reaching maximum values of 325 , 239 , and $309 \mathrm{mg} / \mathrm{g}$ at 27,35 , and $45^{\circ} \mathrm{C}$, respectively.

3.3. Adsorption Isotherms. In this study, equilibrium data were analyzed with the Langmuir and BET adsorption isotherm models at 27,35 , and $45^{\circ} \mathrm{C}$. The Langmuir model describes a single-layer adsorption process [47]. The following equations correspond to the nonlinear form (Equation
(3)) and the linearized form (4) of the Langmuir isotherm model [48]:

$$
\begin{aligned}
q_{e} & =\frac{q_{\max } K_{L} C_{e}}{1+K_{L} C_{e}}, \\
\frac{C_{e}}{q_{e}} & =\frac{1}{q_{\max }} \times C_{e}+\frac{1}{q_{\max } K_{L}} .
\end{aligned}
$$

In these equations, $q_{\max }$ is the maximum adsorbent capacity $(\mathrm{mg} / \mathrm{g})$ and $K_{L}$ is the Langmuir adsorption constant $(\mathrm{L} / \mathrm{mg})$. The constants of the Langmuir model $\left(q_{\max }\right.$ and $\left.K_{L}\right)$ can be evaluated either by nonlinear fitting from (3) or by calculating the slope and the intercept of the linear fitting plot (4), which describes $\left(C_{e} / q_{e}\right)$ as a function of $C_{e}$.

The BET model, which is an extension of the Langmuir model, assumes a multilayer adsorption process. The following equations correspond to the nonlinear (5) and linearized form (Equation (6)) of the BET isotherm model [49]:

$$
\begin{aligned}
q_{e} & =\frac{q_{\max } K_{B} C_{e}}{\left(C_{s}-C_{e}\right)\left[1+\left(K_{B}-1\right) C_{e} / C_{s}\right]}, \\
\frac{C_{e}}{\left(C_{s}-C_{e}\right) q_{e}} & =\frac{K_{B}-1}{K_{B} q_{\max }} \times \frac{C_{e}}{C_{s}}+\frac{1}{K_{B} q_{\max }} .
\end{aligned}
$$

In these equations, $K_{B}$ is the BET adsorption constant $(\mathrm{L} / \mathrm{mg})$ and $C_{s}$ the saturation concentration of $\mathrm{Pb}(\mathrm{II})(\mathrm{mg} / \mathrm{L})$. Both nonlinear and linearized forms of the Langmuir ((3)-(4)) and BET ( (5)-(6)) isotherms for $\mathrm{Pb}(\mathrm{II})$ adsorption at $27^{\circ} \mathrm{C}$ are plotted in Figures 7(a) and 7(b), respectively. Both models could be well fit to the experimental data. Standard nonlinear and linear fitting algorithms (Figure 7) were used to estimate the model parameters, $q_{\max }$ and $K_{L}$, for the Langmuir model, and $q_{\max }$ and $K_{B}$, for the BET model (Table 2). Good fitting results were obtained for both Langmuir and BET models, although the BET model predicted lower values for the maximal capacity of $\mathrm{Pb}(\mathrm{II})$ adsorption at $35^{\circ} \mathrm{C}$. The Langmuir value was $234.7 \mathrm{mg} / \mathrm{g}$, whereas the BET value was $162.3 \mathrm{mg} / \mathrm{g}$.

The maximal capacity of $\mathrm{Pb}$ (II) adsorption on MOF-5 was estimated to be $658.5 \mathrm{mg} / \mathrm{g}$ (at $45^{\circ} \mathrm{C}$ ) using the Langmuir model with the assumption that adsorption occurs in a specific homogeneous place (single layer). This value is higher than those obtained by other studies with different materials. For example, Wu et al. [9] obtained a $q_{\max }$ value of $130.2 \mathrm{mg} / \mathrm{g}$, 


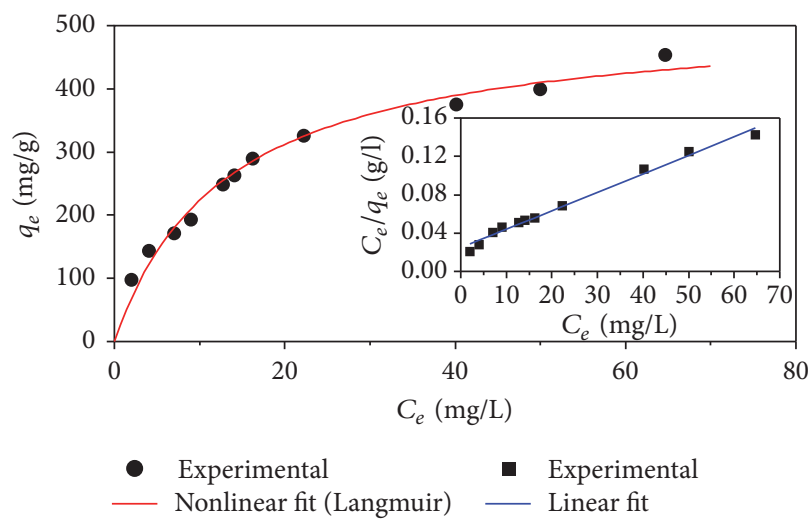

(a)

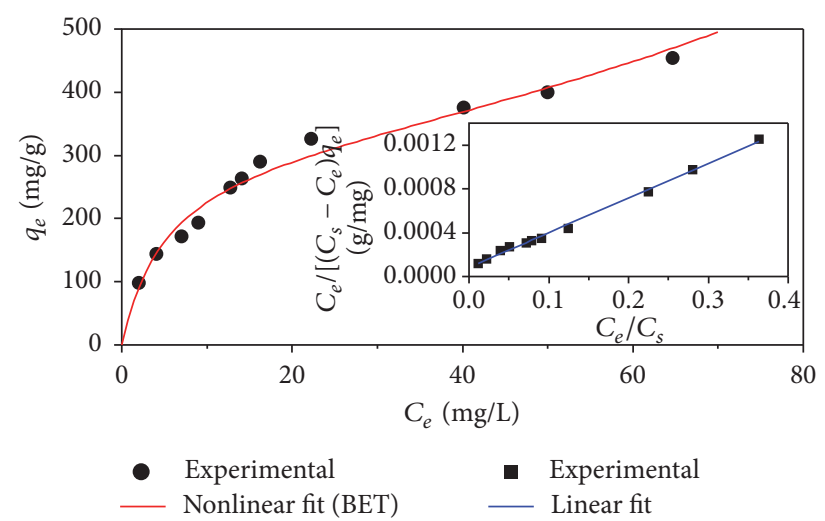

(b)

Figure 7: Adsorption isotherms for $\mathrm{Pb}(\mathrm{II})$ adsorption over MOF-5 at $27^{\circ} \mathrm{C}$ and $\mathrm{pH}$ 5. Nonlinear and linear fitting for the Langmuir model (a) and the BET model (b).

TABLE 2: Langmuir and BET isotherm constants for the adsorption of $\mathrm{Pb}(\mathrm{II})$ with $\mathrm{MOF}-5$ using nonlinear form (upper value) and linearized form (lower value).

\begin{tabular}{|c|c|c|c|c|c|c|c|c|}
\hline \multirow{2}{*}{$T\left({ }^{\circ} \mathrm{C}\right)$} & \multicolumn{4}{|c|}{ Langmuir model } & \multicolumn{4}{|c|}{ BET model } \\
\hline & Equation & $q_{\max }(\mathrm{mg} / \mathrm{g})$ & $K_{L}(\mathrm{~L} / \mathrm{mg})$ & $R^{2}$ & Equation & $q_{\max }(\mathrm{mg} / \mathrm{g})$ & $K_{B}(\mathrm{~L} / \mathrm{mg})$ & $R^{2}$ \\
\hline \multirow{2}{*}{27} & (3) & 517.6 & 0.076 & 0.98 & (5) & 323.2 & 68.5 & 0.98 \\
\hline & (4) & 517.4 & 0.078 & 0.98 & $(6)$ & 315.9 & 38.3 & 0.99 \\
\hline \multirow{2}{*}{35} & (3) & 234.7 & 0.518 & 0.81 & (5) & 162.3 & 353.1 & 0.91 \\
\hline & (4) & 256.1 & 0.330 & 0.99 & (6) & 156.5 & 1390.3 & 0.99 \\
\hline \multirow{2}{*}{45} & (3) & 658.5 & 0.046 & 0.98 & (5) & 412.7 & 15.6 & 0.99 \\
\hline & (4) & 657.6 & 0.047 & 0.94 & $(6)$ & 418.4 & 7.6 & 0.97 \\
\hline
\end{tabular}

which corresponds to only $20 \%$ of the capacity obtained in this work (Table 3). These high $\mathrm{Pb}$ (II) removal capacities obtained in aqueous media with MOF- 5 may be explained by the interaction between the $\mathrm{BDC}^{2-}$ and $\mathrm{Pb}(\mathrm{II})$, as reported by Greathouse and Allendorf [31].

3.4. Adsorptive Removal Kinetics. A kinetic study of $\mathrm{Pb}(\mathrm{II})$ removal with MOF-5 was carried out with an initial concentration of $200 \mathrm{mg} / \mathrm{L}$, a $\mathrm{pH}$ of 5 , and at $27^{\circ} \mathrm{C}$ with contact times ranging from 0 to $6 \mathrm{~h}$ (Figure $8(\mathrm{a})$ ). The results showed that maximum $\mathrm{Pb}$ (II) removal occurs during the first $30 \mathrm{~min}$, reaching $55 \pm 1 \%$ of the total $\mathrm{Pb}$ (II) removal, which may be explained by the high availability of $\mathrm{BCD}^{-2}$. After this initial period, the amount of adsorbed $\mathrm{Pb}$ (II) nearly stops as equilibrium is attained.

A pseudo-second-order kinetic model [50] was used to analyze the $\mathrm{Pb}(\mathrm{II})$ removal kinetics (Figure $8(\mathrm{~b})$ ). Its nonlinear form is given by the following equation:

$$
q_{t}=\frac{k_{2} q_{e}^{2} t}{1+k_{2} q_{e} t} .
$$

Its most common linearized form is given by

$$
\frac{t}{q_{t}}=\frac{1}{k_{2} q_{e}^{2}}+\frac{1}{q_{e}} t .
$$

Here, $q_{e}(\mathrm{mg} / \mathrm{g})$ is the sorption capacity at equilibrium, $q_{t}$ $(\mathrm{mg} / \mathrm{g})$ is the sorption capacity at time $t(\mathrm{~h})$, and $k_{2}$ is the rate constant. The initial rate of adsorption $(h)(\mathrm{mg} / \mathrm{g} \mathrm{min})$ can also be calculated by using the following relation [51]:

$$
h=k_{2} q_{e}^{2}
$$

As shown in Figure 8(b), adequate agreement between the model and experimental data was obtained using both the standard nonlinear and linear fitting procedures. High correlation coefficients (0.99) were obtained. The predicted values of $q_{e}$ are also are close to those found experimentally, suggesting that the adsorption of $\mathrm{Pb}$ (II) onto MOF-5 follows pseudo-second-order kinetics. The initial adsorption rate $(h)$, as calculated using (9), was $17 \%$ higher (19.88 $\mathrm{mg} / \mathrm{g} \mathrm{min}$ ) than the values reported by Sheela and Nayaka [51] for $\mathrm{Pb}$ (II) adsorption with $\mathrm{NiO}$ nanoparticles $(16.45 \mathrm{mg} / \mathrm{g} \mathrm{min})$. This difference may be attributed to increased active sites $\left(\mathrm{BDC}^{2-}\right.$ ) where $\mathrm{Pb}(\mathrm{II})$ may coordinate to be adsorbed.

3.5. Effect of $\mathrm{pH}$ on $\mathrm{Pb}$ (II) Removal. The removal of $\mathrm{Pb}$ (II) from aqueous media was measured (at $27^{\circ} \mathrm{C}$ ) at different $\mathrm{pH}$ values, adjusted by the addition of $\mathrm{NaOH}$, to reach $\mathrm{pH}$ 6 , and $\mathrm{HCl}$, for $\mathrm{pH} 4$ (Figure 9). MOF-5 showed relatively high removal capacities at $\mathrm{pH} 4$ and 6,750 , and $660 \mathrm{mg} / \mathrm{g}$, respectively, but a low value at $\mathrm{pH} 5(450 \mathrm{mg} / \mathrm{g}$, without $\mathrm{pH}$ adjustment). This behavior may be related to the structure of MOF-5 which has the peculiarity of possessing both acid and basic active sites [52] that may be activated by the change in the $\mathrm{pH}$ value (Figure 9). 
TABLE 3: Comparison of maximum adsorption capacity of $\mathrm{Pb}(\mathrm{II})$ using different materials.

\begin{tabular}{lcc}
\hline Adsorbent & Capacity $(\mathrm{mg} / \mathrm{g})$ & Reference \\
\hline Amino-functionalized MNPs & 40.10 & Hao et al. 2012 [27] \\
Magnetic nanoadsorbents & 36.00 & Nassar 2010 [28] \\
Magnetic nanocomposite beads-chitosan & 63.33 & Tran et al. 2010 [29] \\
Hydroxyapatite & 1429 & Yan et al. 2014 [11] \\
Biochar-alginate capsule & 263.15 & Do and Lee 2013 [12] \\
Chitosan/fe-hydroxyapatite & 596.7 & Saber-Samandari et al. 2014 [13] \\
Dry desulfurization slag & 130.2 & Wu et al. 2014 [9] \\
MOF-5 & 658.50 & This study \\
\hline
\end{tabular}

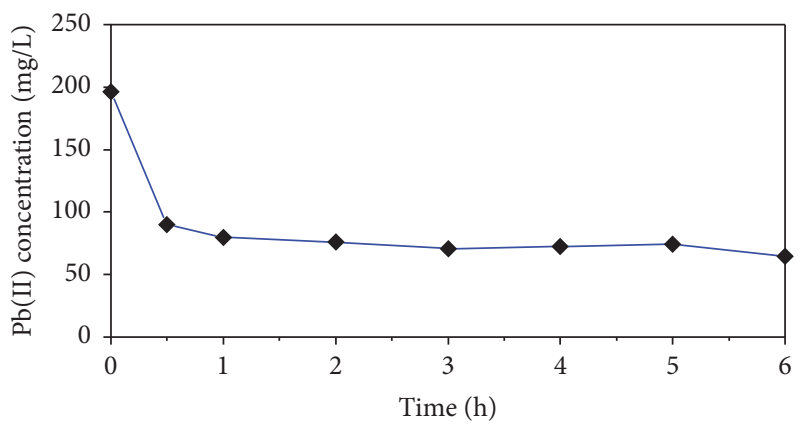

(a)

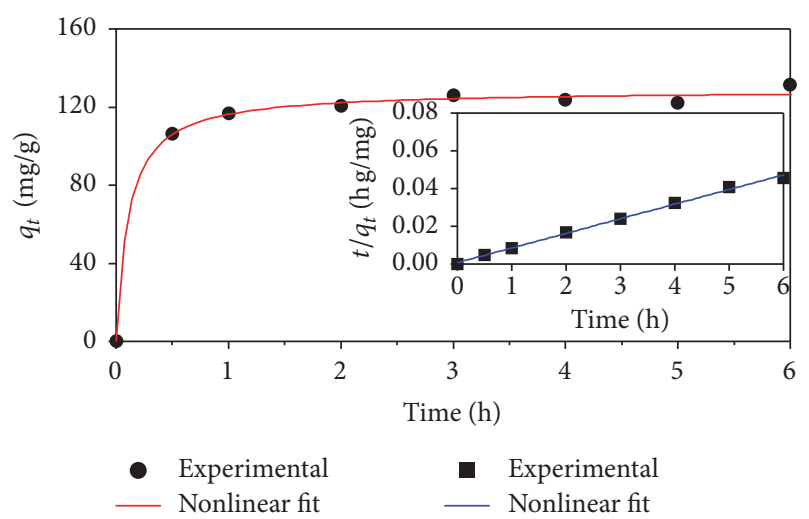

(b)

FIgURE 8: Time evolution of adsorptive removal of $\mathrm{Pb}$ (II) (a) and pseudo-second-order kinetics of $\mathrm{Pb}$ (II) adsorption onto MOF-5 (b) at $200 \mathrm{mg} / \mathrm{L}$ initial $\mathrm{Pb}(\mathrm{II}), 27^{\circ} \mathrm{C}$ and $\mathrm{pH} 5$.

\section{Conclusions}

This study demonstrated that MOF-5 performed adequately the adsorption of $\mathrm{Pb}(\mathrm{II})$ from aqueous media through a possible process of interaction $\left(\mathrm{BDC}^{2-}\right.$ with $\left.\mathrm{Pb}(\mathrm{II})\right)$ that involved $\mathrm{Zn}$ (II) liberation and morphological change of the adsorbent, as shown by SEM-EDX and XPS results. The adsorption of $\mathrm{Pb}(\mathrm{II})$ formed a monolayer according to the Langmuir model with a high adsorptive capacity $(658.5 \mathrm{mg} / \mathrm{g})$ at $\mathrm{pH} 5$ and $45^{\circ} \mathrm{C}$. Furthermore the adsorptive removal capacity of $\mathrm{Pb}(\mathrm{II})$ may be improved by changing the $\mathrm{pH}$ of the aqueous solution. We may conclude that MOF-5 could be very effective adsorbent material for $\mathrm{Pb}(\mathrm{II})$ removal from

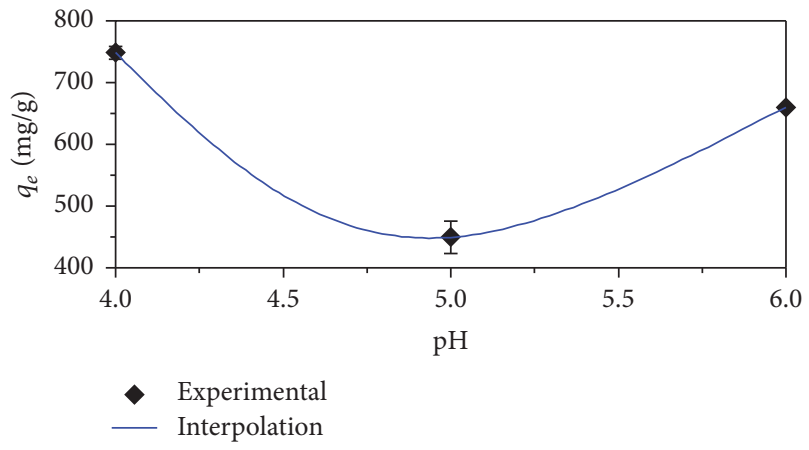

Figure 9: The $\mathrm{pH}$ effect on the adsorption of $\mathrm{Pb}(\mathrm{II})$ onto MOF-5 using an initial concentration of $\mathrm{Pb}(\mathrm{II})$ of $200 \mathrm{mg} / \mathrm{L}$ at $27^{\circ} \mathrm{C}$.

wastewaters in spite of the loss of the structural stability provoked by the presence of water.

\section{Nomenclature}

$C_{0}: \quad$ Initial concentration of $\mathrm{Pb}(\mathrm{II})(\mathrm{mg} / \mathrm{L})$

$\mathrm{C}_{e}: \quad$ Equilibrium concentration of $\mathrm{Pb}(\mathrm{II})(\mathrm{mg} / \mathrm{L})$

$C_{s}: \quad$ Saturation concentration of $\mathrm{Pb}(\mathrm{II})(\mathrm{mg} / \mathrm{L})$

$h$ : Initial rate of adsorption ( $\mathrm{mg} / \mathrm{g} \mathrm{min})$

$K_{L}$ : Langmuir adsorption constant $(\mathrm{L} / \mathrm{mg})$

$K_{B}: \quad$ BET adsorption constant $(\mathrm{L} / \mathrm{mg})$

$k_{2}$ : Rate constant of the pseudo-second-order kinetic model (g/(mg h))

$q_{e}: \quad$ Equilibrium adsorption capacity $(\mathrm{mg} / \mathrm{g})$

$q_{\max }:$ Maximum monolayer adsorption capacity $(\mathrm{mg} / \mathrm{g})$

$q_{t}: \quad$ Equilibrium adsorption at time $t(\mathrm{mg} / \mathrm{g})$

$q_{B}$ : Maximum multilayer adsorption capacity $(\mathrm{mg} / \mathrm{g})$

$V: \quad$ Volume of $\mathrm{Pb}(\mathrm{II})$ solution (L)

$W$ : Weight of MOF-5 (g).

\section{Competing Interests}

The authors declare that there is no conflict of interests regarding the publication of this paper.

\section{Authors' Contributions}

José María Rivera and Susana Rincón contributed equally to this work. 


\section{Acknowledgments}

This research was supported by CONACYT (169563). The authors wish to thank the National Laboratory of Nano and Biomaterials (CONACyT) of the CINVESTAV-Mérida for realizing the SEM-EDX, FTIR, XPS, and XRD analysis, in particular Ph.D. degree holder Patricia Quintana, M.S. degree holder Dora Huerta Quintanilla, Biologist Ana Cristóbal Ramos, and M.S. degree holder Daniel Aguilar Treviño.

\section{References}

[1] L. Niu, S. B. Deng, G. Yu, and J. Huang, "Efficient removal of $\mathrm{Cu}(\mathrm{II}), \mathrm{Pb}(\mathrm{II}), \mathrm{Cr}(\mathrm{VI})$ and $\mathrm{As}(\mathrm{V})$ from aqueous solution using an aminated resin prepared by surface-initiated atom transfer radical polymerization," Chemical Engineering Journal, vol. 165, no. 3, pp. 751-757, 2010.

[2] A. T. Paulino, L. B. Santos, and J. Nozaki, "Removal of $\mathrm{Pb}^{2+}, \mathrm{Cu}^{2+}$ and $\mathrm{Fe}^{3+}$ from battery manufacture wastewater by chitosan produced from silkworm chrysalides as a low-cost adsorbent," Reactive and Functional Polymers, vol. 68, no. 2, pp. 634-642, 2008.

[3] K. N. Dietrich, J. H. Ware, M. Salganik et al., "Effect of chelation therapy on the neuropsychological and behavioral development of lead-exposed children after school entry," Pediatrics, vol. 114, no. 1, pp. 19-26, 2004.

[4] K. He, S. Wang, and J. Zhang, "Blood lead levels of children and its trend in China," Science of the Total Environment, vol. 407, no. 13, pp. 3986-3993, 2009.

[5] US EPA, "Nutrient criteria tehnical guidance manual: lakes and reservoirs," Document EPA 822-D-99-001, United States Enviromental Protection Agency (USEPA), 1999.

[6] M. E. Argun, S. Dursun, M. Karatas, and M. Gürü, "Activation of pine cone using Fenton oxidation for $\mathrm{Cd}(\mathrm{II})$ and $\mathrm{Pb}(\mathrm{II})$ removal," Bioresource Technology, vol. 99, no. 18, pp. 8691-8698, 2008.

[7] H. Ghassabzadeh, M. Torab-Mostaedi, A. Mohaddespour, M. G. Maragheh, S. J. Ahmadi, and P. Zaheri, "Characterizations of Co (II) and $\mathrm{Pb}$ (II) removal process from aqueous solutions using expanded perlite," Desalination, vol. 261, no. 1-2, pp. 73-79, 2010.

[8] K. Kadirvelu, K. Thamaraiselvi, and C. Namasivayam, "Removal of heavy metals from industrial wastewaters by adsorption onto activated carbon prepared from an agricultural solid waste," Bioresource Technology, vol. 76, no. 1, pp. 63-65, 2001.

[9] Q. Wu, R. You, M. Clark, and Y. Yu, "Pb(II) removal from aqueous solution by a low-cost adsorbent dry desulfurization slag," Applied Surface Science, vol. 314, pp. 129-137, 2014.

[10] J.-X. Yu, L.-Y. Wang, R.-A. Chi, Y.-F. Zhang, Z.-G. Xu, and J. Guo, "Competitive adsorption of $\mathrm{Pb}^{2+}$ and $\mathrm{Cd}^{2+}$ on magnetic modified sugarcane bagasse prepared by two simple steps," Applied Surface Science, vol. 268, pp. 163-170, 2013.

[11] Y. Yan, Y. Wang, X. Sun et al., "Optimizing production of hydroxyapatite from alkaline residue for removal of $\mathrm{Pb}^{2+}$ from wastewater," Applied Surface Science, vol. 317, pp. 946-954, 2014.

[12] X.-H. Do and B.-K. Lee, "Removal of Pb2+ using a biocharalginate capsule in aqueous solution and capsule regeneration," Journal of Environmental Management, vol. 131, pp. 375-382, 2013.

[13] S. Saber-Samandari, S. Saber-Samandari, N. Nezafati, and K. Yahya, "Efficient removal of lead (II) ions and methylene blue from aqueous solution using chitosan/Fe-hydroxyapatite nanocomposite beads," Journal of Environmental Management, vol. 146, pp. 481-490, 2014.

[14] K. Ariga, S. Ishihara, H. Abe, M. Li, and J. P. Hill, "Materials nanoarchitectonics for environmental remediation and sensing," Journal of Materials Chemistry, vol. 22, no. 6, pp. 23692377, 2012.

[15] J.-R. Li, J. Sculley, and H.-C. Zhou, "Metal-organic frameworks for separations," Chemical Reviews, vol. 112, no. 2, pp. 869-932, 2012.

[16] A. Vinu and K. Ariga, "New ideas for mesoporous materials," Advanced Porous Materials, vol. 1, no. 1, pp. 63-71, 2013.

[17] Z. Chen, S. Xiang, D. Zhao, and B. Chen, "Reversible two-dimensional-three dimensional framework transformation within a prototype metal-organic framework," Crystal Growth and Design, vol. 9, no. 12, pp. 5293-5296, 2009.

[18] C. Chen, M. Zhang, Q. Guan, and W. Li, "Kinetic and thermodynamic studies on the adsorption of xylenol orange onto MIL101(Cr)," Chemical Engineering Journal, vol. 183, pp. 60-67, 2012.

[19] E. Haque, J. E. Lee, I. T. Jang et al., "Adsorptive removal of methyl orange from aqueous solution with metal-organic frameworks, porous chromium-benzenedicarboxylates," Journal of Hazardous Materials, vol. 181, no. 1-3, pp. 535-542, 2010.

[20] Z. Hasan, J. Jeon, and S. H. Jhung, "Adsorptive removal of naproxen and clofibric acid from water using metal-organic frameworks," Journal of Hazardous Materials, vol. 209-210, pp. 151-157, 2012.

[21] Z. Hasan and S. H. Jhung, "Removal of hazardous organics from water using metal-organic frameworks (MOFs): plausible mechanisms for selective adsorptions," Journal of Hazardous Materials, vol. 283, pp. 329-339, 2015.

[22] F. Ke, L.-G. Qiu, Y.-P. Yuan et al., “Thiol-functionalization of metal-organic framework by a facile coordination-based postsynthetic strategy and enhanced removal of $\mathrm{Hg}^{2+}$ from water," Journal of Hazardous Materials, vol. 196, pp. 36-43, 2011.

[23] M. Maes, S. Schouteden, L. Alaerts, D. Depla, and D. E. De Vos, "Extracting organic contaminants from water using the metal-organic framework $\mathrm{Cr}^{I I I}(\mathrm{OH}) \cdot \mathrm{O}_{2} \mathrm{C}-\mathrm{C}_{6} \mathrm{H}_{4}-\mathrm{CO}_{2}$," Physical Chemistry Chemical Physics, vol. 13, no. 13, pp. 5587-5589, 2011.

[24] K. Yang, Q. Sun, F. Xue, and D. Lin, "Adsorption of volatile organic compounds by metal-organic frameworks MIL-101: influence of molecular size and shape," Journal of Hazardous Materials, vol. 195, pp. 124-131, 2011.

[25] N. Bakhtiari and S. Azizian, "Adsorption of copper ion from aqueous solution by nanoporous MOF-5: a kinetic and equilibrium study," Journal of Molecular Liquids, vol. 206, pp. 114-118, 2015.

[26] N. A. Rodríguez, R. Parra, and M. A. Grela, "Structural characterization, optical properties and photocatalytic activity of MOF-5 and its hydrolysis products: implications on their excitation mechanism," RSC Advances, vol. 5, no. 89, pp. 7311273118, 2015.

[27] S. Y. Hao, Y. J. Zhong, F. Pepe, and W. Zhu, "Adsorption of $\mathrm{Pb}^{2+}$ and $\mathrm{Cu}^{2+}$ on anionic surfactant-templated aminofunctionalized mesoporous silicas," Chemical Engineering Journal, vol. 189-190, pp. 160-167, 2012.

[28] N. N. Nassar, "Rapid removal and recovery of $\mathrm{Pb}$ (II) from wastewater by magnetic nanoadsorbents," Journal of Hazardous Materials, vol. 184, no. 1-3, pp. 538-546, 2010.

[29] H. V. Tran, L. D. Tran, and T. N. Nguyen, "Preparation of chitosan/magnetite composite beads and their application for 
removal of $\mathrm{Pb}(\mathrm{II})$ and $\mathrm{Ni}(\mathrm{II})$ from aqueous solution," Materials Science and Engineering C, vol. 30, no. 2, pp. 304-310, 2010.

[30] J. Hafizovic, M. Bjørgen, U. Olsbye et al., "The inconsistency in adsorption properties and powder XRD data of MOF-5 is rationalized by framework interpenetration and the presence of organic and inorganic species in the nanocavities," Journal of the American Chemical Society, vol. 129, no. 12, pp. 3612-3620, 2007.

[31] J. A. Greathouse and M. D. Allendorf, "The interaction of water with MOF-5 simulated by molecular dynamics," Journal of the American Chemical Society, vol. 128, no. 33, pp. 10678-10679, 2006.

[32] M. Eddaoudi, H. Li, and O. M. Yaghi, "Highly porous and stable metal-organic frameworks: structure design and sorption properties," Journal of the American Chemical Society, vol. 122, no. 7, pp. 1391-1397, 2000.

[33] S. L. James, "Metal-organic frameworks," Chemical Society Reviews, vol. 32, no. 5, pp. 276-288, 2003.

[34] S. Keskin and S. Kizilel, "Biomedical applications of metal organic frameworks," Industrial and Engineering Chemistry Research, vol. 50, no. 4, pp. 1799-1812, 2011.

[35] S. Keskin and D. S. Sholl, "Efficient methods for screening of metal organic framework membranes for gas separations using atomically detailed models," Langmuir, vol. 25, no. 19, pp. 1178611795, 2009.

[36] A. V. Neimark, F.-X. Coudert, C. Triguero et al., "Structural transitions in MIL-53 (Cr): view from outside and inside," Langmuir, vol. 27, no. 8, pp. 4734-4741, 2011.

[37] S. Das, H. Kim, and O. Kim, "Metathesis in single crystal: complete and reversible exchange of metal ions constituting the frameworks of metal-organic frameworks," Journal of the American Chemical Society, vol. 131, no. 11, pp. 3814-3815, 2009.

[38] N. Iswarya, M. G. Kumar, K. S. Rajan, and R. J. B. Balaguru, "Synthesis, characterization and adsorption capability of MOF5," Asian Journal of Scientific Research, vol. 5, no. 4, pp. 247-254, 2012.

[39] R. Sabouni, H. Kazemian, and S. Rohani, "A novel combined manufacturing technique for rapid production of IRMOF-1 using ultrasound and microwave energies," Chemical Engineering Journal, vol. 165, no. 3, pp. 966-973, 2010.

[40] J. E. Huheey, E. A. Keiter, A. Ellen et al., Inorganic Chemistry: Principles of Structure and Reactivity, Harper Collings College Publishers, 4th edition, 1993.

[41] J. Coates, "Interpretation of infrared spectra: a practical approach," in Encyclopedia of Analytical Chemistry, R. A. Meyers, Ed., pp. 10815-10837, John Wiley \& Sons, New York, NY, USA, 2000.

[42] N. T. S. Phan, K. K. A. Le, and T. D. Phan, "MOF-5 as an efficient heterogeneous catalyst for Friedel-Crafts alkylation reactions," Applied Catalysis A: General, vol. 382, no. 2, pp. 246-253, 2010.

[43] B. R. Strohmeier, "Zinc aluminate $\left(\mathrm{ZnAl}_{2} \mathrm{O}_{4}\right)$ by XPS," Surface Science Spectra, vol. 3, no. 2, pp. 128-134, 1994.

[44] L. Y. Wu, H. J. Wang, H. C. Lan, H. Liu, and J. Qu, "Adsorption of $\mathrm{Cu}(\mathrm{II})$-EDTA chelates on tri-ammonium-functionalized mesoporous silica from aqueous solution," Separation and Purification Technology, vol. 117, pp. 118-123, 2013.

[45] J. Chastain and J. F. Moulder, Handbook of X-ray Photoelectron Spectroscopy: A Reference Book of Standard Spectra for Identification and Interpretation of XPS Data, Perkin-Elmer, Eden Prairie, Minn, USA, 1992.

[46] H. S. Liu, T. S. Chin, and S. W. Yung, "FTIR and XPS studies of low-melting $\mathrm{PbO}-\mathrm{ZnO}-\mathrm{P}_{2} \mathrm{O}_{5}$ glasses," Materials Chemistry and Physics, vol. 50, no. 1, pp. 1-10, 1997.
[47] I. Langmuir, "The constitution and fundamental properties of solids and liquids. Part I. Solids," Journal of the American Chemical Society, vol. 38, no. 2, pp. 2221-2295, 1916.

[48] B. H. Hameed and A. A. Rahman, "Removal of phenol from aqueous solutions by adsorption onto activated carbon prepared from biomass material," Journal of Hazardous Materials, vol. 160, no. 2-3, pp. 576-581, 2008.

[49] K. Y. Foo and B. H. Hameed, "Insights into the modeling of adsorption isotherm systems," Chemical Engineering Journal, vol. 156, no. 1, pp. 2-10, 2010.

[50] R. Rostamian, M. Najafi, and A. A. Rafati, "Synthesis and characterization of thiol-functionalized silica nano hollow sphere as a novel adsorbent for removal of poisonous heavy metal ions from water: kinetics, isotherms and error analysis," Chemical Engineering Journal, vol. 171, no. 3, pp. 1004-1011, 2011.

[51] T. Sheela and Y. A. Nayaka, "Kinetics and thermodynamics of cadmium and lead ions adsorption on $\mathrm{NiO}$ nanoparticles," Chemical Engineering Journal, vol. 191, pp. 123-131, 2012.

[52] L. Wang, B. Xiao, G. Y. Wang, and J. Wu, "Synthesis of polycarbonate diol catalyzed by metal-organic framework $\mathrm{Zn}_{4} \mathrm{O}\left[\mathrm{CO}_{2}\right.$ $\left.\mathrm{C}_{6} \mathrm{H}_{4}-\mathrm{CO}_{2}\right]_{3}$," Science China Chemistry, vol. 54, no. 9, pp. $1468-$ 1473, 2011. 

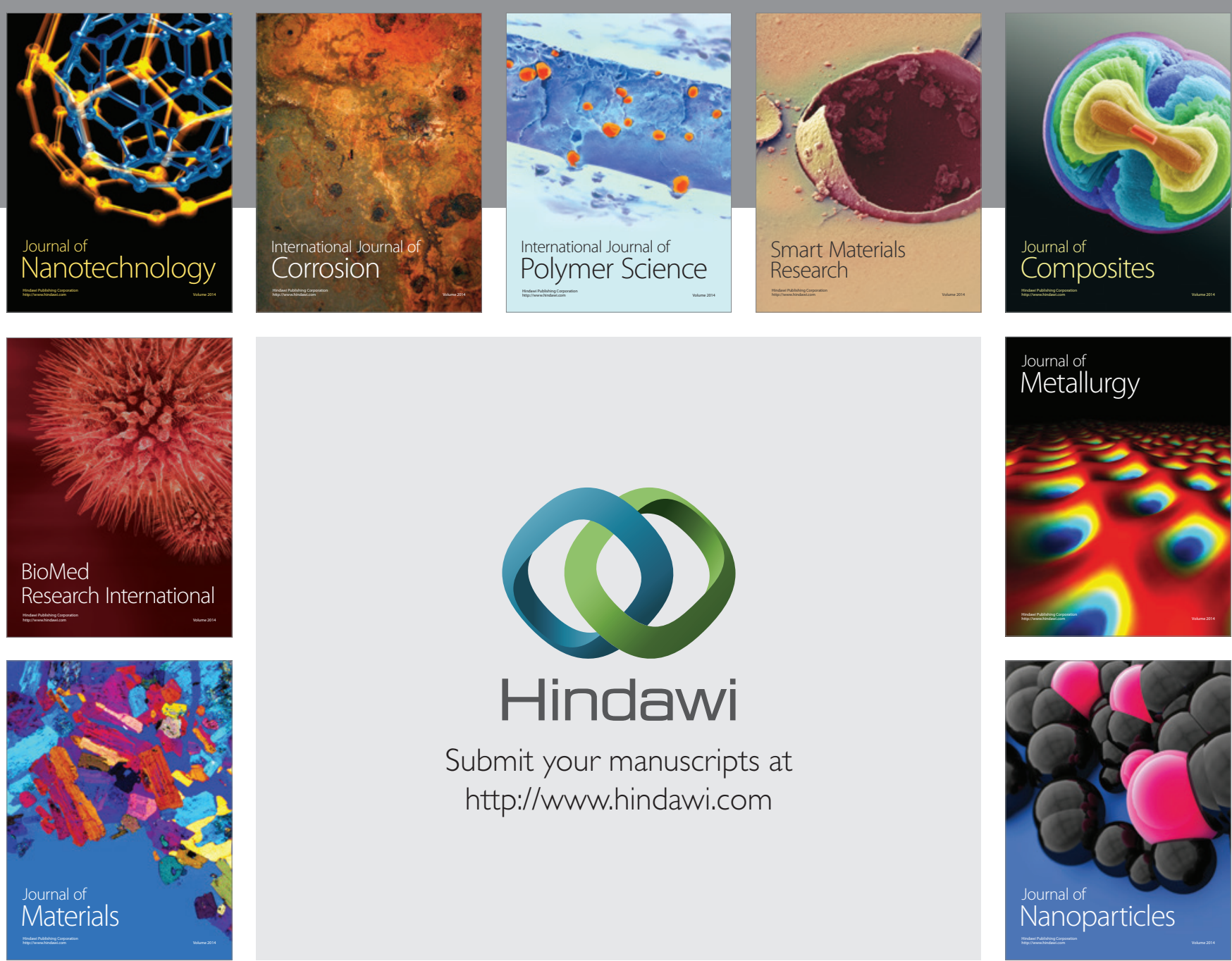

\section{Hindawi}

Submit your manuscripts at

http://www.hindawi.com

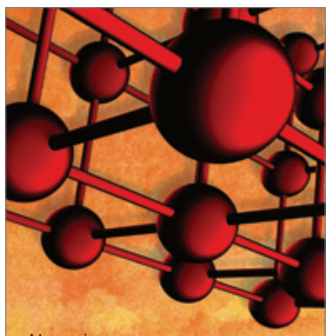

Materials Science and Engineering
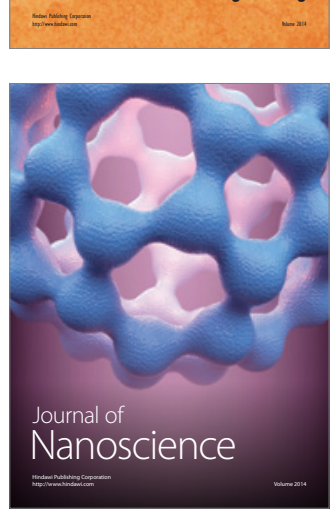
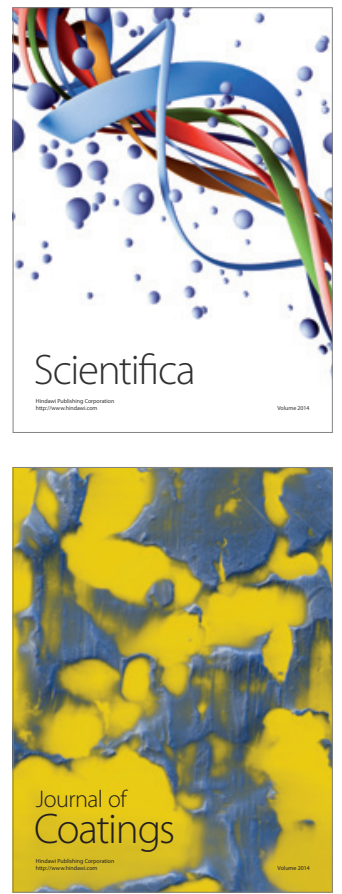
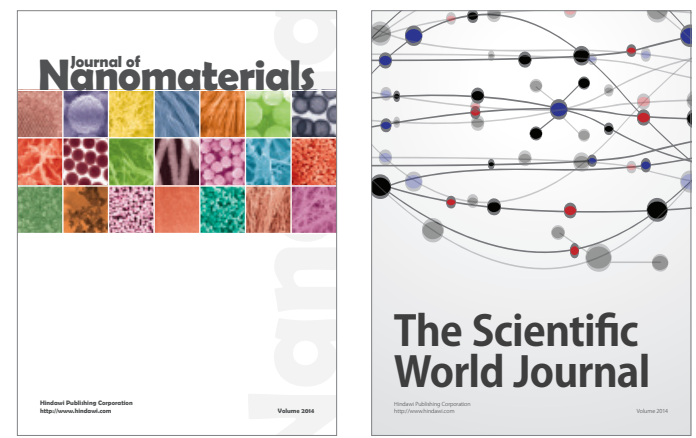

The Scientific World Journal
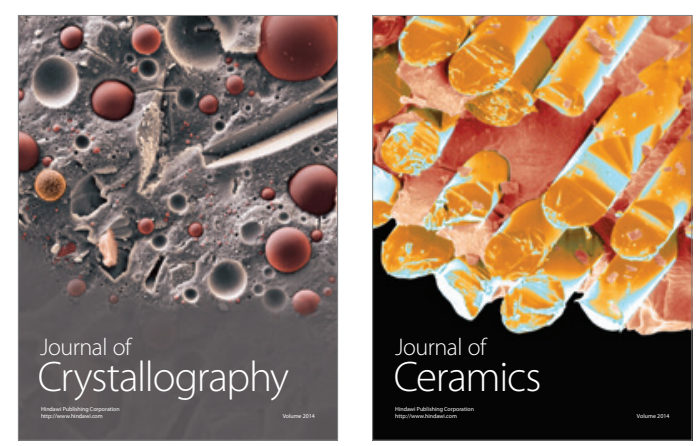
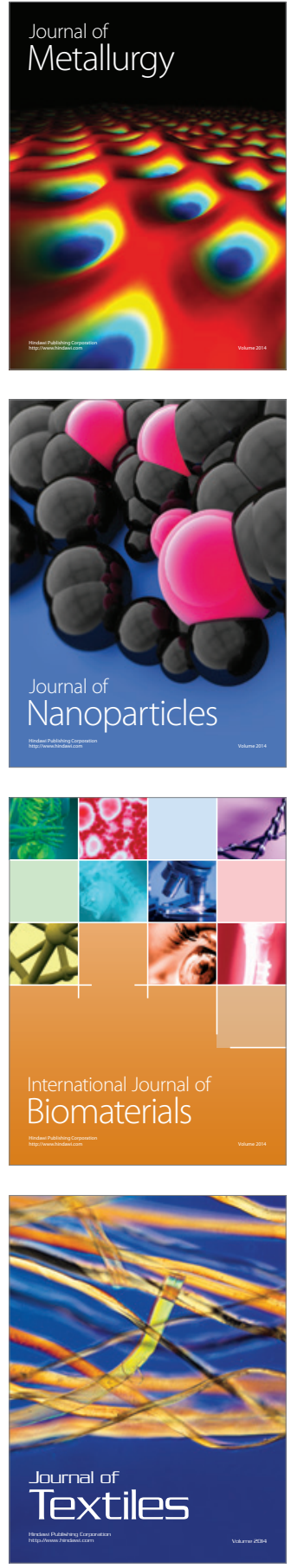